Probing active sites during palladium-catalyzed alcohol oxidation in "supercritical" carbon dioxide

\author{
Journal Article \\ Author(s): \\ Grunwaldt, Jan-Dierk; Caravati, Matteo; Ramin, Michael; Baiker, Alfons \\ Publication date: \\ 2003-10 \\ Permanent link: \\ https://doi.org/10.3929/ethz-b-000052981
}

Rights / license:

In Copyright - Non-Commercial Use Permitted

Originally published in:

Catalysis Letters 90(3-4), https://doi.org/10.1023/B:CATL.0000004121.26500.ee 


\title{
Probing active sites during palladium-catalyzed alcohol oxidation in "supercritical" carbon dioxide
}

\author{
Jan-Dierk Grunwaldt*, Matteo Caravati, Michael Ramin, and Alfons Baiker \\ Institute for Chemical and Bioengineering, Swiss Federal Institute of Technology, ETH Hönggerberg HCI, CH-8093 Zurich, Switzerland
}

Received 27 May 2003; accepted 7 August 2003

\begin{abstract}
Structural information has been gained during aerobic benzyl alcohol oxidation in "supercritical" carbon dioxide at 150 bar on alumina-supported palladium by X-ray absorption spectroscopy while monitoring simultaneously the performance of the catalyst. The reduction of the catalyst by benzyl alcohol could be monitored by the analysis of the near-edge region of the Pd K-edge. The palladium constituent was mainly in metallic state under operating conditions. Partial reoxidation was observed when only oxygen in "supercritical" carbon dioxide in the absence of alcohol was fed. The catalytic activity of the $\mathrm{PdO}_{x} / \mathrm{Al}_{2} \mathrm{O}_{3}$ catalyst during benzyl alcohol oxidation was comparable to that in a conventional continuous fixed-bed reactor and depended on the oxygen concentration in the feed. The rate of alcohol conversion went through a maximum when the oxygen concentration was increased. At maximum rate, part of the palladium was in the oxidized state. Upon further increase of the oxygen concentration, the activity decreased because of the formation of surface palladium oxide. The reaction rate in "supercritical" carbon dioxide was strikingly higher than that observed for the corresponding liquid-phase oxidation.
\end{abstract}

KEY WORDS: supercritical carbon dioxide; green chemistry; alcohol oxidation; $\mathrm{Pd} / \mathrm{Al}_{2} \mathrm{O}_{3} ; \mathrm{EXAFS}$; XANES; in situ spectroscopy; high-pressure spectroscopy.

\section{Introduction}

"Supercritical" (dense) carbon dioxide as "green" solvent has received significant interest in chemical reactions, in particular, in homogeneous and heterogeneous catalysis (cf. references [1-7] and references therein). Because of the special properties of "supercritical" fluids (SCFs), parameters such as density, solvent power, and viscosity are intermediate between those of gases and liquids. Since the term "supercritical" is clearly defined only for pure fluids (cf. reference [8]), it is used here in quotes for a dense fluid phase at temperatures exceeding its mixture critical point (irrespective of further liquid phases being present). "Supercritical" carbon dioxide is interesting as a solvent because it is relatively cheap, nonflammable, and exhibits fair and tunable solubility for weakly polar (water-insoluble) compounds. In solid-catalyzed reactions, in particular, continuous-flow processing using "supercritical" carbon dioxide is interesting [5,7]. The beneficial use of SCFs with respect to rate and/or selectivity has been demonstrated for several heterogeneously catalyzed reactions (recent examples, e.g. in references [5-7]). Among them, oxidation reactions are interesting because of the inertness of carbon dioxide toward molecular oxygen [9-12].

Despite the fact that reactions often show increased rate or selectivity under "supercritical" conditions, fundamental understanding is often lagging behind

\footnotetext{
* To whom correspondence should be addressed
}

and there is strong need for suitable spectroscopic techniques [7]. Both unraveling the phase behavior [5,7,8,13-15] and monitoring of the solid catalyst under reaction conditions are indispensable. Owing to the demanding conditions required during spectroscopic monitoring, only a few studies have been reported to characterize the structure of the solid catalyst and the solid-fluid interface in SCFs $[16,17]$.

In the present study, we thus focus on the identification of the solid catalyst phase under reaction conditions. The oxidation of alcohols over $\mathrm{PdO}_{x} / \mathrm{Al}_{2} \mathrm{O}_{3}$ is presented as a case study. The catalytic activity depends strongly on the amount of oxygen in the feed [9]. Higher rates have been found in "supercritical" carbon dioxide in comparison to vapor-phase oxidation [9] and deactivation is lower than that in liquid phase [12]. Hence, the question arises as to which oxidation state palladium exhibits under these conditions and whether this parameter relates to the performance of the catalyst. Ideally, simultaneous determination of the catalytic performance and the structure of the catalyst under these demanding conditions is required for elucidating the structure-activity relationships.

Apart from attenuated total reflection infrared spectroscopy (ATR-IR, e.g. references $[16,17]$ ), X-ray absorption spectroscopy (XAS) is a valuable technique for operando spectroscopy because it can give direct information on the oxidation state of noble metal atoms [18]. Though X-ray absorption spectroscopy has not been used for unraveling the catalyst structure in SCFs, the technique was widely used for identification of the 
structure at the gas-solid interface [18-26] under reaction conditions, leading in ideal cases to structureactivity relationships [24,26-30]. For liquid-solid reactions, in situ EXAFS studies are rarer, but are equally powerful [31,32]. Using the QEXAFS method and a continuous-flow reactor system, dynamic changes of a solid catalyst can be studied in liquid phase as well [33].

Hence, the extension of this technique to heterogeneously catalyzed reactions in $\mathrm{scCO}_{2}$ (or $\mathrm{SCF}$ in general) is conclusive. This requires suitable highpressure equipment and an appropriate in situ cell. Only a few XAS cells have been reported for moderate pressure [34-36]. High-pressure cells, mainly using beryllium windows [37], a quartz capillary, [38] or a diamond anvil $[39,40]$ have been used for identifying the structure of metal complexes [41-45], the local structure of solvents, [37] or homogeneous reactions in SCFs [38]. But investigation of solids leads to complicating requirements [7], i.e., a design that allows spectroscopic studies on a heterogeneous sample and warrants optimal flow/mass-transport properties.

Here, we report on the first example where a solidcatalyzed reaction was studied in $\mathrm{scCO}_{2}$ in an in situ spectroscopic cell designed for simultaneous XAS and catalytic studies. As a model reaction, the aerobic benzyl alcohol oxidation in "supercritical" $\mathrm{CO}_{2}$ was chosen (scheme 1). First, the reduction of palladium by alcohol at $150 \mathrm{bar}$ in dense $\mathrm{CO}_{2}$ was investigated. Then, we studied the catalyst under reaction conditions and information on both the structure, i.e., the oxidation state of palladium (from the near-edge structure), and the catalytic behavior was extracted simultaneously.

\section{Experimental}

\subsection{Materials}

A commercial shell-impregnated catalyst consisting of $0.5 \mathrm{wt} \% \mathrm{Pd} / \mathrm{Al}_{2} \mathrm{O}_{3}$ (Engelhard) was used as a sieved fraction (ca. 0.5-1.4 mm). Benzyl alcohol (Fluka, purity $>99.0 \%$ ) was used as received. Carbon dioxide was fed in liquid form (Linde, 99.995\%) and pure oxygen (Linde, $99.995 \%$ ) as gas (180 bar). For reductive pretreatment of the catalyst, premixed $5 \% \mathrm{H}_{2} / \mathrm{He}$ (Messer-Griesheim, 99.9995\%) was applied.

\subsection{Partial oxidation of benzyl alcohol in a conventional continuous fixed-bed reactor}

Oxidation experiments according to scheme 1 were carried out isothermally in a continuous fixed-bed reactor with an inner diameter of $13-\mathrm{mm}$ and $38-\mathrm{mL}$ volume, similar to that described, e.g., in reference [10]. Benzyl alcohol was dosed by a Gilson 305 piston pump. Oxygen was supplied to the reactor using a six-port valve dosing $0.05 \mathrm{~mL}$ pulses at high pressure and constant frequency. The constant pressure in the system was maintained by a back-pressure regulator with carbon dioxide. The total gas flow was controlled at the vent. The standard conditions described in this study were $150 \mathrm{bar}$ and a total flow of $0.11 \mathrm{~mol} / \mathrm{min}$. The alcohol feed was kept constant at $0.002 \mathrm{~mol} / \mathrm{min}$, while the oxygen feed was varied between 0.001 and $0.02 \mathrm{~mol} /$ min. Samples of the liquid products were taken after separation from $\mathrm{CO}_{2}$ and analyzed by GC (HP-6890, FFAP column).

\subsection{Partial oxidation of benzyl alcohol in the EXAFS reactor cell}

In order to establish realistic reaction conditions during the spectroscopic studies, high-pressure equipment was used during operando spectroscopy that is usually applied for high-pressure reactions in conventional continuous fixed-bed reactors. Due to spectroscopic and safety reasons, the volume of the cell was kept much smaller than in the conventional continuousflow fixed-bed reactor $(0.5 \mathrm{~mL})$. In principal, we gave special attention during the construction and the studies to the following aspects in order to ensure optimal conditions both for spectroscopy and catalysis: (i) the shape and textural properties of the catalyst is similar to those of the real catalyst (solid catalyst phase, fixed bed to warrant ideal liquid flow and liquid-solid mass transfer, shell-type catalyst to avoid intraparticle diffusion phenomena); (ii) the design is kept similar to the continuous-flow cell used during the reaction; (iii) the reactor cell is equipped with $\mathrm{X}$-ray transmittant windows (Be pellets) that withstand a pressure $>100$ bar; and (iv) samples are taken during structural analysis.

The principle flowchart in figure 1 gives an overview on the performed experiment. Note that the complexity of the experimental setup is higher compared to that used for corresponding continuous-flow fixed-bed reac-

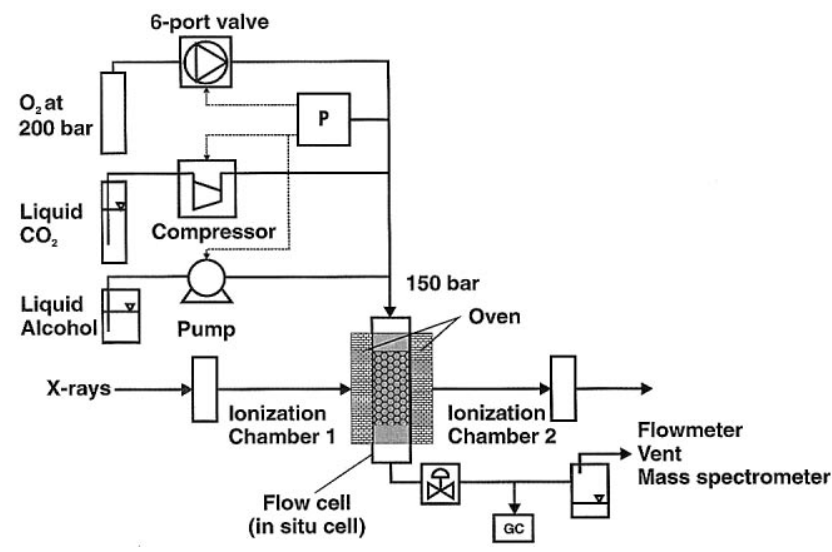

Figure 1. Flow scheme for the in situ continuous-flow XAS cell to combine structural analysis by XAS and catalytic activity by GC; more details in the text. 

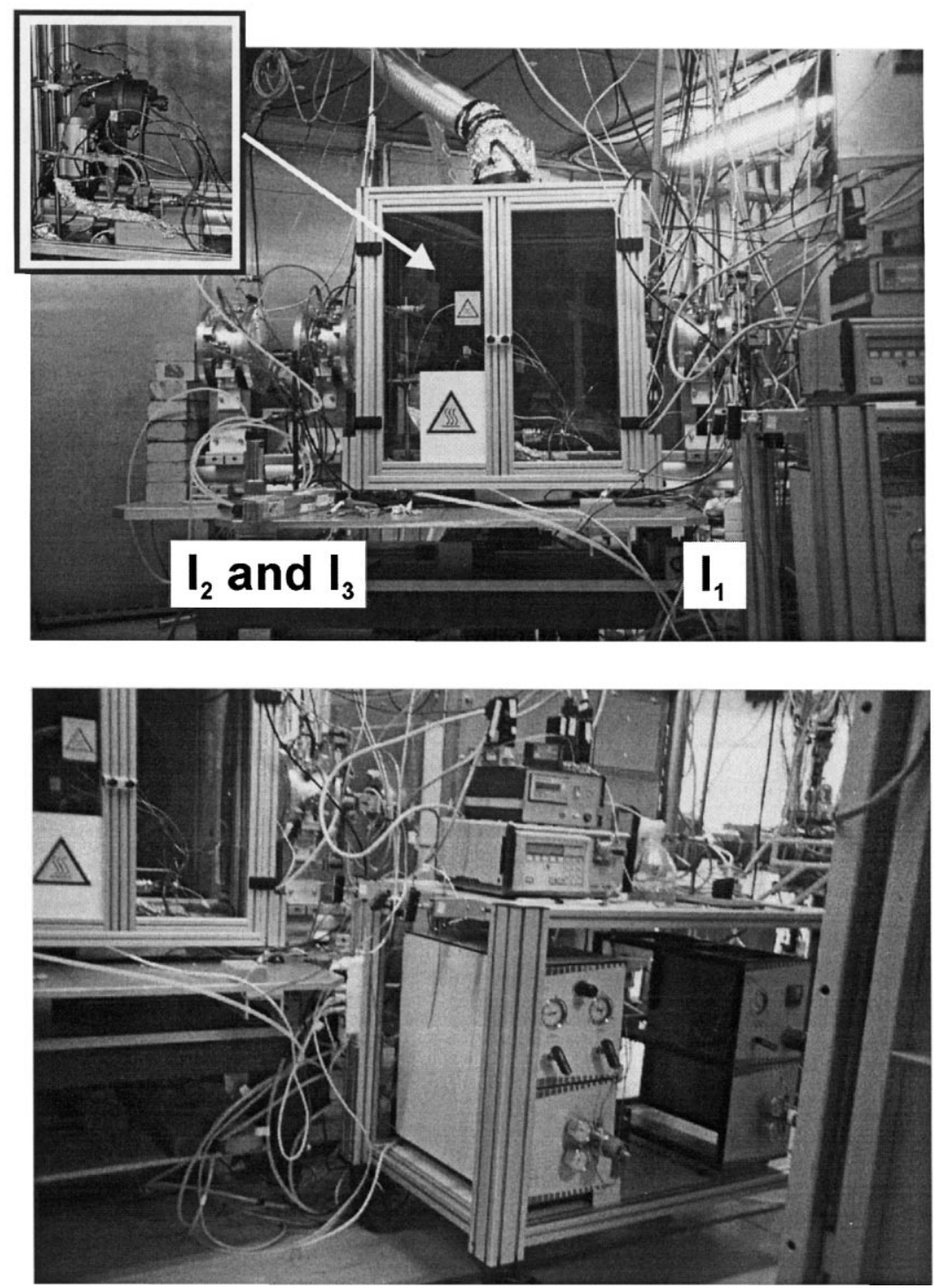

Figure 2. Photographs of the in situ setup at the synchrotron beamline in Hamburg: upper part shows the box in which the oven including the in situ cell are installed, the lower picture shows the compressor, the liquid pump and the expansion unit on a movable wagon used for rapid installation of the experiment.

tor experiments in liquid-solid [20,33] or gaseous-solid systems $[22,24,27,46-48]$. This is also evident from figure 2 , which shows the corresponding setup at the beamline at Hamburger Synchrotronlabor (HASYLAB at DESY, Germany) at beamline X1.

From the flowchart (figure 1), the following components used for the oxidation of benzyl alcohol in $\mathrm{scCO}_{2}$ can be seen. Liquid carbon dioxide is compressed by a $\mathrm{CO}_{2}$-compressing unit (NWA PM-101) to 150-250 bar and fed via a reduction valve to the reactor. Oxygen (at about 180 bar pressure) is introduced into the system by a six-port valve (RHEODYNE 7000) and the alcohol is fed by a Gilson piston pump. The reaction mixture is fed over the catalyst and expanded in an expansion unit (NWA PE-103) from 150 bar to normal pressure. The pressure is measured just before the inlet of the reactor cell where a burst plate is also located in order to prevent the cell from unexpected too-high pressure. In addition, an electronic manometer was used both for reading out the pressure and for an automatic shutdown of the compressing unit, the six-port valve, and the liquid pump, in case the pressure would be higher than a predefined value. The gas at the outlet was vented to the exhaust system and on-line gas monitoring was performed by a mass spectrometer (Balzers), both during reduction of the catalyst in hydrogen and during reaction (monitoring of carbon dioxide, oxygen, and water). The in situ cell consists of two 3-mm thick beryllium windows with a diameter of $10 \mathrm{~mm}$ on both sites of the catalyst compartment. The cell volume is about $0.5 \mathrm{~mL}$ and is filled with the catalyst (sieved fraction, ca. $0.5 \mathrm{~mm}$ ). The inlet of the fluid is at the upper side, while the outlet is located at the bottom of the cell. The catalyst powder is placed between two glass 
wool plugs that hold the catalyst in its position. The cell is then attached to an oven that is fixed on an $x, y, \theta$ table. The $x, y, \theta$-table itself is mounted on the X95profile (Newport), usually available at the beamline. For safety reasons, the whole setup including the in situ cell, the oven, and the aligning unit is placed in a protection box, as can be seen in figure 2 .

The in situ cell was tested in advance at SITEC Sieber Engineering AG at 300 bar, ensuring measurements of at least 200 bar. Principally, the design of the cell also allows investigations at higher pressure. Typical measurements were made at $150 \mathrm{bar}$, using a total flow of $0.11 \mathrm{~mol} / \mathrm{min}$ (alcohol feed rate of $0.002 \mathrm{~mol} / \mathrm{min}$ and oxygen feed rate varied between 0.001 and $0.004 \mathrm{~mol} /$ $\min )$.

Safety Note: The experiments described in this paper involve the use of relatively high pressure and require equipment with the appropriate pressure rating.

\subsection{XAS experiments}

The XAS experiments were performed at the Hamburger Synchrotronlabor (HASYLAB at DESY, Germany) at beamline X1 using a $\mathrm{Si}(311)$ double crystal monochromator. Higher harmonics were effectively removed by detuning of the crystals to $70 \%$ of the maximum intensity. Three ionization chambers filled with Ar were used to record the intensity of the incident and the transmitted X-rays (in situ reactor cell located between the first and second ionization chamber, a Pdreference foil for energy calibration between the second and third ionization chamber). Under stationary conditions, EXAFS spectra were taken around the Pd K-edge in the step scanning mode between 24000 and $25800 \mathrm{eV}$. Additionally, faster scans around the edge were recorded using the normal step scanning EXAFS mode or the continuous EXAFS scanning mode between 24320 and $24500 \mathrm{eV}(6-30 \mathrm{~min} / \mathrm{scan})$. The raw data were energy-calibrated ( $\mathrm{Pd} \mathrm{K}$-edge energy of the Pd-foil: $24350 \mathrm{eV}$, first inflection point), smoothed, background corrected, and normalized using the WINXAS 2.1 software [49]. In order to quantify the relative ratio of $\mathrm{Pd}^{0} / \mathrm{Pd}^{2+}$, linear combination analysis of the XANES region between 24.34 and $24.44 \mathrm{keV}$ was performed, using the spectra of the completely reduced (after hydrogen treatment) and the in-air oxidized $\mathrm{Pd} / \mathrm{Al}_{2} \mathrm{O}_{3}$ catalyst as model spectra.

\section{Results}

\subsection{Benzyl alcohol oxidation in "supercritical" carbon dioxide as function of oxygen partial pressure}

The benzyl alcohol oxidation rate as a function of the oxygen concentration according to the reaction shown in scheme 1 is depicted in figure 3. A clear dependence of

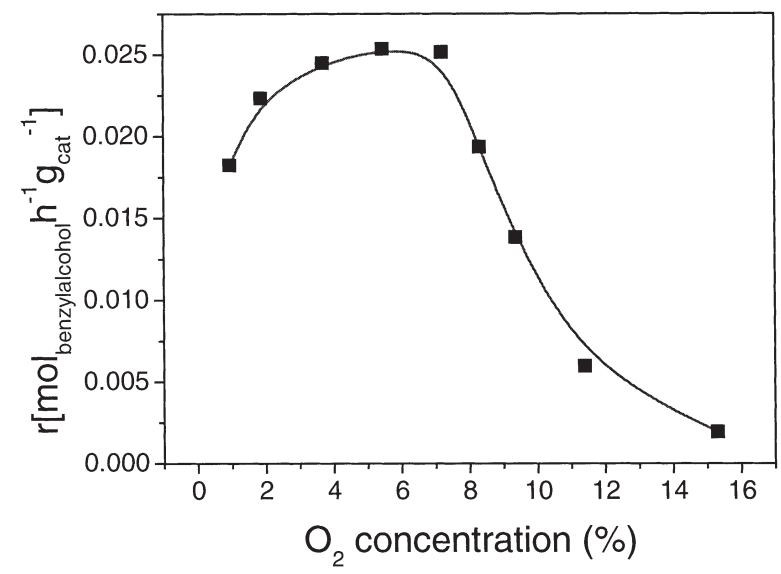

Figure 3. Dependence of the rate of benzyl alcohol oxidation on the oxygen concentration in the feed; conditions: $80^{\circ} \mathrm{C}, 150 \mathrm{bar}$, total flow $0.11 \mathrm{~mol} / \mathrm{min}$ (alcohol concentration $1.9 \%$ ), $5 \mathrm{~g}$ of $0.5 \% \mathrm{PdO}_{x} / \mathrm{Al}_{2} \mathrm{O}_{3}$, over several days of equilibrated catalyst.

the rate on the oxygen concentration was found reaching its maximum at about $6 \%$ of oxygen in the feed. The selectivity to benzaldehyde (cf. scheme 1) was relatively

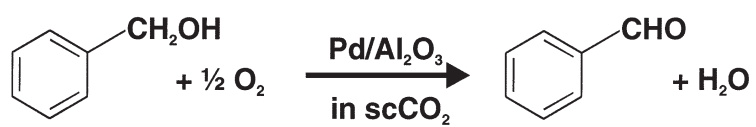

high (around 95\%) and only small amounts of the corresponding acid and ester were identified. Interestingly, a similar dependence of the alcohol oxidation rate from the oxygen concentration was also observed for the oxidation of 2-octanol, and it can be speculated that the rate first increases because of the increase of one of the reactants (oxygen) and that at high oxygen concentrations a so-called "overoxidation" (cf. references [50,51]) of palladium occurs, leading to surface palladium oxide, which is less active than palladium in the nearly reduced state [10].

In order to prove this hypothesis, in situ studies are necessary. Note that the turnover frequency was $>1000 \mathrm{~h}^{-1}$. Mimicking the applied reaction conditions in a liquid (water, organic solvent) under continuousflow conditions is difficult because of the low solubility of oxygen in the solvent. It is also difficult to transfer the reaction to the gas phase because benzyl alcohol would be in liquid state under reaction conditions. Thus, in situ studies are preferentially performed under similar conditions as applied in the experiments shown in figure 3 , i.e., similar flow rate, similar fluid composition, temperature, and pressure.

\subsection{Comparison of the reduction of alumina-supported palladium by benzyl alcohol in "supercritical" $\mathrm{CO}_{2}$ and in hydrogen in the gas phase}

In the pursuit of probing the catalyst phase under supercritical conditions, we monitored the as-prepared 


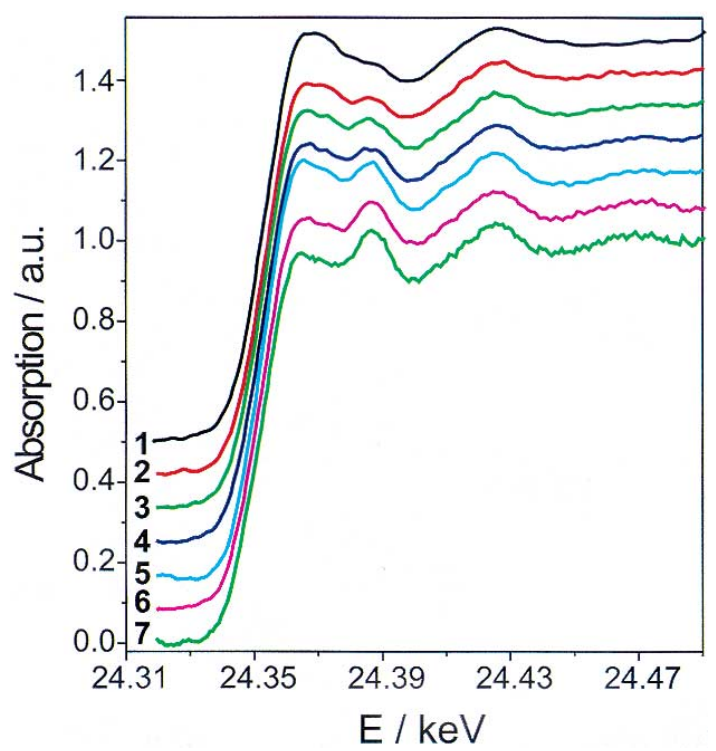

Figure 4. Time resolved X-ray absorption spectra around the Pd Kedge during reduction of $\mathrm{PdO}_{x} / \mathrm{Al}_{2} \mathrm{O}_{3}$ by benzyl alcohol; conditions: $80^{\circ} \mathrm{C}, 150 \mathrm{bar}$, alcohol feed rate $0.002 \mathrm{~mol} / \mathrm{min}, 0.3 \mathrm{~g}$ catalyst: (1) asprepared catalyst in "supercritical" $\mathrm{CO}_{2}$ without alcohol feed; (2) start of alcohol in $\mathrm{scCO}_{2}$; (3) $6 \mathrm{~min}$ in alcohol $/ \mathrm{scCO}_{2}$; (4) $12 \mathrm{~min}$ in alcohol $/ \mathrm{scCO}_{2}$; (5) $24 \mathrm{~min}$ in alcohol $/ \mathrm{scCO}_{2}, 100{ }^{\circ} \mathrm{C}$; (6) $30 \mathrm{~min}$ in alcohol $/ \mathrm{scCO}_{2}, 100{ }^{\circ} \mathrm{C}$; (7) $48 \mathrm{~min}$ in alcohol $/ \mathrm{scCO}_{2}, 100^{\circ} \mathrm{C}$.

catalyst in "supercritical" carbon dioxide at $80^{\circ} \mathrm{C}$ and followed the structural changes during benzyl alcohol additions. The results are depicted in figure 4. For comparison, the spectra of $\mathrm{Pd}-$ foil and $\mathrm{PdO}$ as references and the reduction in hydrogen is also shown (figure 5). The spectra during reduction were taken in the continuous scanning mode (QEXAFS [52]).

In both cases, palladium oxide, originating from previous exposure of the catalyst to air, is reduced, as uncovered by the decrease of the whiteline at $24.362 \mathrm{eV}$. While the reduction of $\mathrm{PdO}_{x} / \mathrm{Al}_{2} \mathrm{O}_{3}$ in hydrogen already partly occurred at room temperature, reduction by benzyl alcohol requires higher temperatures, here performed at $80^{\circ} \mathrm{C}$. In a previous study, reduction of a $5 \mathrm{wt} \% \mathrm{PdO}_{x} / \mathrm{Al}_{2} \mathrm{O}_{3}$ catalyst was studied by cinnamyl alcohol in toluene [33]. The reduction was faster in the present case, which can be due to different reasons: (a) higher reaction temperature, (b) higher diffusion rates in "supercritical" fluids, or (c) the catalyst in this study is a shell-impregnated catalyst to avoid intraparticle diffusion limitation. The reduction potential of benzyl alcohol and cinnamyl alcohol is similar and thus differences caused by this factor should be small.

Careful comparison of the catalyst reduced in hydrogen and that reduced in alcohol uncovers that the palladium after alcohol reduction is slightly less reduced (pronounced oscillation between 24.35 and $24.40 \mathrm{keV}$, not shown). This is also supported by a quantitative analysis (linear combination analysis of the near-edge spectra), showing a small amount of palladium $(<10 \%)$ still being in the oxidized state. Since this was not observed in the previous study by EXAFS
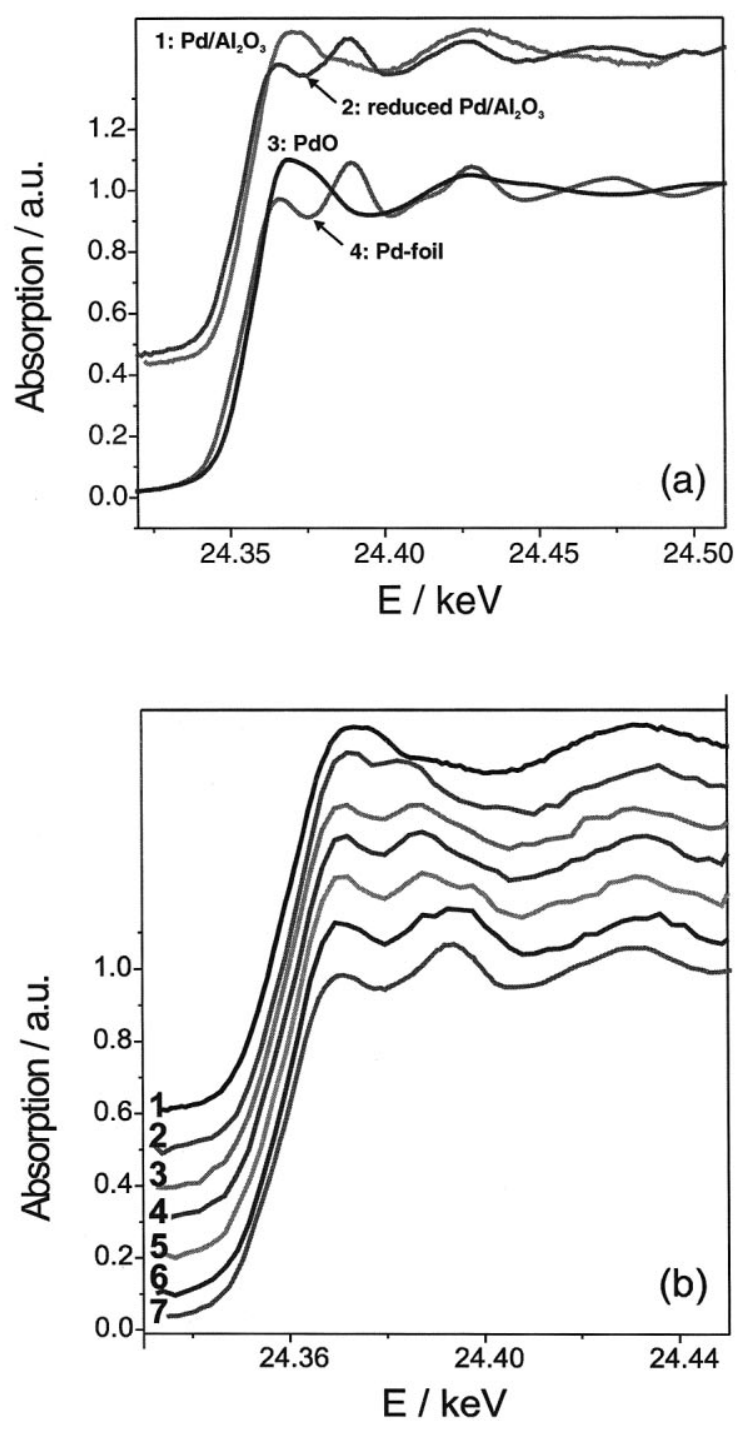

Figure 5. (a) Comparison of the as-prepared alumina-supported palladium catalysts (1) and the same catalyst reduced in the in situ cell in hydrogen at $100^{\circ} \mathrm{C}$ (2) to a PdO model sample (3) and Pd-foil (4); (b) time-resolved X-ray absorption spectra around the Pd K-edge during reduction of $0.5 \% \mathrm{PdO}_{x} / \mathrm{Al}_{2} \mathrm{O}_{3}$ by $5 \% \mathrm{H}_{2} / \mathrm{He}$ (1) room temperature, (2) directly after change to $\mathrm{H}_{2}$, (3) $5 \mathrm{~min}$ in $\mathrm{H}_{2}$, (4) start of heating to $100^{\circ} \mathrm{C},(5) 50^{\circ} \mathrm{C},(6) 70^{\circ} \mathrm{C},(8) 100^{\circ} \mathrm{C}$.

analysis [33], this may be due to the different particle size of the $\mathrm{Pd} / \mathrm{Al}_{2} \mathrm{O}_{3}$ catalyst in the recent study. Some changes are also expected due to palladium hydride formation in the presence of hydrogen. The reduction of $\mathrm{PdO}_{x} / \mathrm{Al}_{2} \mathrm{O}_{3}$ by benzyl alcohol in " $\mathrm{scCO}_{2}$ " illustrates the potential of in situ XAFS for the characterization of solid catalysts under the demanding reaction conditions of SCFs.

\subsection{Monitoring of structure and activity during alcohol oxidation in "supercritical" $\mathrm{CO}_{2}$}

The next step was to uncover the oxidation state of palladium under working conditions. Both the catalytic activity and the near-edge structure of the PdK-edge 
Table 1

Catalytic results obtained during aerobic oxidation of benzyl alcohol. The experiments were performed in the order indicated in the table. The relative $\mathrm{Pd}^{0} / \mathrm{Pd}^{2+}$ ratio was determined by linear combination analysis from the XANES data (see text), the catalytic activity was simultaneously determined using GC-analysis

\begin{tabular}{|c|c|c|c|c|c|c|c|c|c|}
\hline \multirow{2}{*}{$\frac{\text { Experimental conditions }}{\text { Experiment }}$} & \multirow{2}{*}{$\begin{array}{c}\text { Alcohol }=0 \%{ }^{\mathrm{a}} \\
\mathrm{O}_{2}=0 \% \\
1\end{array}$} & \multicolumn{2}{|c|}{$\begin{array}{c}\text { Alcohol }=1.9 \%{ }^{\mathrm{a}} \\
\mathrm{O}_{2}=0.95 \%\end{array}$} & \multicolumn{3}{|c|}{$\begin{array}{c}\text { Alcohol }=1.9 \%^{\mathrm{a}} \\
\quad \mathrm{O}_{2}=1.9 \%\end{array}$} & \multirow{2}{*}{$\begin{array}{c}\text { Alcohol }=0 \%^{\mathrm{a}} \\
\mathrm{O}_{2}=1.9 \% \\
7\end{array}$} & \multicolumn{2}{|c|}{$\begin{array}{c}\text { Alcohol }=1.9 \%^{\mathrm{a}} \\
\quad \mathrm{O}_{2}=1.9 \%\end{array}$} \\
\hline & & 2 & 3 & 4 & 5 & 6 & & 8 & 9 \\
\hline Conversion $(\%)^{\mathrm{b}}$ & - & 5.8 & 5.4 & 7.1 & 7.2 & 7.2 & - & 5.2 & 5.9 \\
\hline $\begin{array}{l}\text { Reaction Rate } \\
\qquad\left(\mathrm{mol}_{\mathrm{Alc}} / \mathrm{h} \cdot \mathrm{g}_{\mathrm{cat}}\right)\end{array}$ & - & 0.022 & 0.021 & 0.027 & 0.028 & 0.028 & - & 0.019 & 0.023 \\
\hline Selectivity $(\%)$ & - & 96.2 & 96.4 & 96.2 & 95.8 & 95.7 & - & 94.4 & 95.3 \\
\hline Relative $\mathrm{Pd}^{0} / \mathrm{Pd}^{2+}$ ratio $^{\mathrm{c}}$ & $0.92 / 0.08$ & $0.87 / 0.13$ & $0.88 / 0.12$ & $0.86 / 0.14$ & - & $0.86 / 0.14$ & $0.67 / 0.33$ & $0.77 / 0.23$ & $0.81 / 0.19$ \\
\hline
\end{tabular}

${ }^{\mathrm{a}}$ All the experiments performed at a total flow of $0.11 \mathrm{~mol} / \mathrm{min}$.

${ }^{\mathrm{b}}$ Determined by GC from the reaction in the in situ EXAFS cell $( \pm 5 \%)$.

${ }^{c}$ Determined by linear combination of the XANES spectra of the catalyst reduced in $5 \% \mathrm{H}_{2} / \mathrm{He}$ and the as-prepared catalyst $( \pm 10 \%)$.

were determined simultaneously. Since the catalyst is usually more active after prereduction in hydrogen, the catalyst was first reduced in hydrogen, then submitted to liquid carbon dioxide, heated to $80^{\circ} \mathrm{C}$, and finally benzyl alcohol and oxygen were added. Both the catalytic performance and structural data are given in table 1 and figure 6, respectively. Some changes in the near-edge structure of the Pd K-edge already occur after addition of the solvent: it seems that the catalyst is either slightly oxidized (figure 6(a)) due to the residual oxygen present in the solvent or, less likely, the near-edge structure of the PdK-edge is influenced by the $\mathrm{CO}_{2}$ itself. However, most of the palladium remains in reduced state if one considers the reduced spectrum in
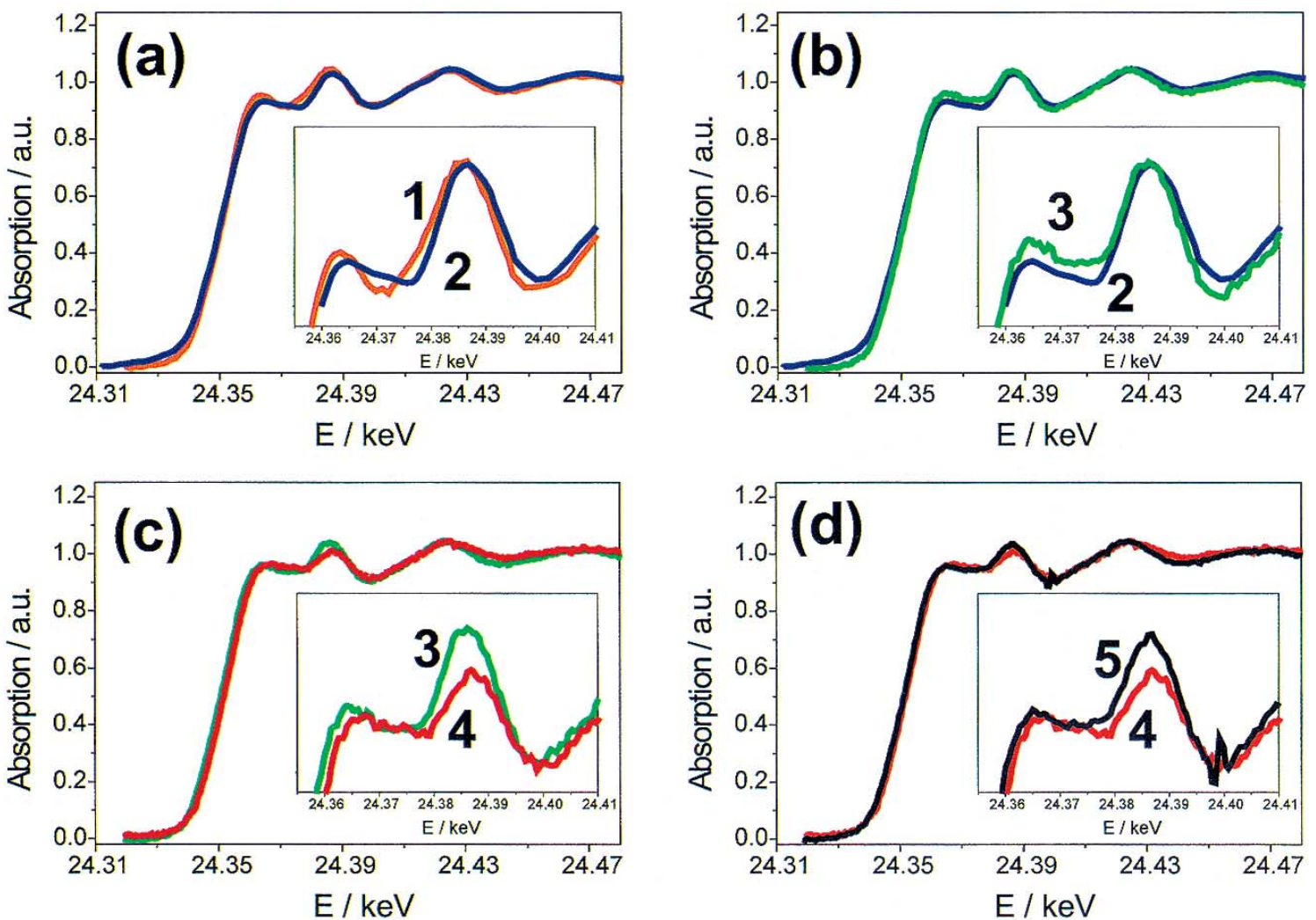

Figure 6. X-ray absorption spectra of $0.5 \% \mathrm{PdO}_{x} / \mathrm{Al}_{2} \mathrm{O}_{3}$ around the $\mathrm{Pd} \mathrm{K}$-edge at different stages of the pretreatment/reaction (zoomed spectra are for better comparison, partly shifted, see also results from LC-analysis and catalysis in table 1): (1) reduced catalysts in hydrogen at $100{ }^{\circ} \mathrm{C}$ (normal pressure); (2) at $80^{\circ} \mathrm{C}, 150 \mathrm{bar}$, only $\mathrm{CO}_{2}$ in the feed, total flow $0.11 \mathrm{~mol} / \mathrm{min}$; (3) during benzyl alcohol oxidation under the following conditions: $80^{\circ} \mathrm{C}, 150 \mathrm{bar}$, total flow $0.11 \mathrm{~mol} / \mathrm{min}$; alcohol concentration $1.9 \%$; oxygen concentration $0.95 \%$; (4) after stop of the alcohol feed and thus the following conditions: $80^{\circ} \mathrm{C}, 150 \mathrm{bar}$, total flow $0.11 \mathrm{~mol} / \mathrm{min}$; oxygen concentration $1.9 \%$; (5) during benzyl alcohol oxidation after oxidation step (4) under the following conditions: $80^{\circ} \mathrm{C}, 150$ bar, total flow $0.11 \mathrm{~mol} / \mathrm{min}$; alcohol concentration $1.9 \%$; oxygen concentration $1.9 \%$. 
figure 5 and the starting spectrum in figure 6 . To extract numerical information from the qualitative changes in figure 6 , we used a linear combination analysis of model spectra for reduced $\mathrm{Pd} / \mathrm{Al}_{2} \mathrm{O}_{3}$ and oxidized $\mathrm{PdO} / \mathrm{Al}_{2} \mathrm{O}_{3}$ (air stored, unused catalyst) around the PdK-edge, which shows that only about $10 \%$ of palladium is reoxidized. While changing to the alcohol/oxygen mixture, small changes due to oxidation of palladium occur, but most of the palladium remains in a metallic state figure 6(b), table 1). The noise of the data is higher than in case of gas-phase spectra, in particular, when performing the reaction above the mixture critical point. The catalytic activity, summarized in table 1 , is very similar to that measured in the continuous fixed-bed reactor, and increases as in figure 3 when adding more oxygen. Only tiny changes in the XANES spectra were observed. A comparison of benzyl alcohol oxidation in $\mathrm{scCO}_{2}$ with that in toluene (similar reaction conditions as in reference [33] using the shell-impregnated $\mathrm{Pd} / \mathrm{Al}_{2} \mathrm{O}_{3}$ catalyst, feed rate about $0.12 \mathrm{~mL} / \mathrm{min}$, $20 \mathrm{mM}$ benzylalcohol in oxygen-saturated toluene) showed that the performance was much better in $\mathrm{scCO}_{2}\left(\mathrm{TOF}>1000 \mathrm{~h}^{-1}\right)$ than in liquid phase $(\mathrm{TOF} \sim$ $\left.20 \mathrm{~h}^{-1}\right)$.

In order to study the behavior, if only oxygen is present in the feed, the alcohol feed was stopped in the next step. As expected, some oxidation of the catalyst was observed (figure 6(c)). Although ca. 2\% of oxygen was present, which corresponds to ca. 3 bar, the catalyst was only partly oxidized. Fitting of the near-edge region of the Pd K-edge shows that about one-third of the palladium is reoxidized (relative ratio).

The process is reversible, as both table 1 and figure 6(d) indicate (compare spectrum (3) and (5) in relation to spectrum (4)). However, a transient is observed and it takes some time until the catalytic activity reaches a steady state again (verified in conventional reactor). In addition, it appears that palladium is not reduced to the same extent again as in the beginning. Also, the catalytic activity is lower than when starting from the completely reduced catalyst. Similar behavior was observed in the conventional continuous reactor (after a sufficient equilibration, the performance was the same).

\section{Discussion}

In situ XAS has been used in a number of studies for the characterization of heterogeneous catalysts in the liquid [31-33] or gaseous phase [18-25]. Here, we have extended its application to a reaction in "supercritical" fluids. The setup for the spectroscopic in situ cell was kept similar to that used for reactions in our laboratory (continuous-flow fixed-bed reactor, shell-impregnated catalyst, use of compressors, etc.). Hence, the flow properties were similar, which thus allowed us to determine the catalytic activity simultaneously to the structural analysis by XAS. As observed in several other reactions in $\mathrm{scCO}_{2}$, the performance of the catalyst was much better in "supercritical" carbon dioxide (TOF $>1000 \mathrm{~s}^{-1}$ ) than in liquid phase (TOF $\sim 20 \mathrm{~s}^{-1}$ ). The importance of in situ studies is discussed in the pertinent literature $[24,26,53,54]$ and the need for in situ monitoring of reactions in SCFs or at elevated pressure have recently been emphasized $[7,55]$. This study now demonstrates how the structure, determined by EXAFS, and the activity can be related at high pressure also. Interesting regions of the catalytic performance, which emerge from more detailed parameter studies performed in the conventional flow-reactor system in the homelaboratory, can thus be selected and studied in more detail at the synchrotron source.

Owing to the high pressure used in the continuousflow fixed-bed reactor system, the spectra turned out to be more noisier than spectra under "normal" conditions. Small variations in pressure ( \pm 1 bar) caused by the unsteady operation of the compressor may result in changes of density that alter the absorption of X-rays by the fluid in the cell. Therefore such studies, although performed in a continuous-flow system, have to be conducted at pressure conditions as stable as possible. Another reason may be the fact that a two-phase mixture is present in the feed. Note that the spectra quality could also be improved by taking high-loaded palladium catalysts. However, XAS is a bulk technique, and in order to gain preferentially surface information, the dispersion should be kept as high as possible while still using a shell-impregnated catalyst. This favors catalysts with low palladium loadings. Therefore, the near-edge region was used for interpretation in this study. From previous studies $[33,56]$, we know that the near-edge region at the $\mathrm{Pd} \mathrm{K}$-edge is very sensitive to the oxidation state of the metal. Preliminary calculations in which we used the FEFF 8.2 code (distributed by University of Washington, cf. reference [57]) supported these conclusions. Palladium atoms directly in neighborhood to an atomically adsorbed oxygen atom showed a clear variation in the whiteline, while those being further away showed only a very small variation.

Application of the in situ technique to the aerobic oxidation of alcohols in "supercritical" carbon dioxide has given interesting insight into the structure of the catalysts. In principle, reactions in SCFs may behave as an intermediate between selective oxidation reactions in liquid phase and gas phase. For liquid-phase reactions, it has been speculated that "overoxidation" of the noble metal catalyst decelerates the reaction [7,9-11]. In situ XAS has uncovered that the palladium constituent during benzyl alcohol oxidation is mainly in the metallic state and that the catalytic activity goes through a maximum when the oxygen concentration is increased. This is in line with a dehydrogenation mechanism postulated for liquid-phase oxidation [51]. At low oxygen coverage, thus adsorbed hydrogen species are 


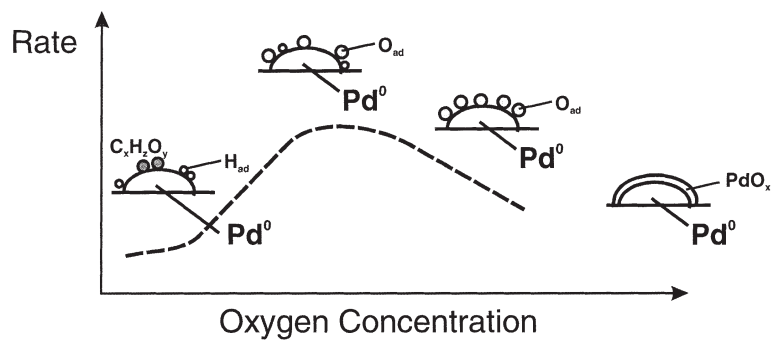

Figure 7. Simplified model for the structure-activity relationship during palladium-catalyzed oxidation of benzyl alcohol in "supercritical" carbon dioxide.

present on the palladium surface keeping it mainly in reduced state as evidenced by in situ XAS. When the oxygen concentration is increased, the rate of benzyl alcohol oxidation passes through a maximum (figure 3).

The spectroscopic and catalytic information obtained in this study and the implication on the mechanism is schematically summarized in figure 7 . At low oxygen concentration (low oxygen coverage), removal of adsorbed hydrogen originating from the dehydrogenation of the alcohol is slow. The oxidation reaction (removal of hydrogen) is thus more effective at higher oxygen concentrations in the feed due to higher surface oxygen coverage. The presence of oxidic species (i.e., adsorbed oxygen, subsurface oxygen) on the palladium particles during optimum conditions is also indicated by the near-edge structure of palladium (table 1, figure 6). Another reason for the improved performance of the palladium catalyst at higher oxygen concentration $(5 \%$ versus $1 \%$ ) may be the removal of carbonaceous species $\left(\mathrm{C}_{x} \mathrm{H}_{y} \mathrm{O}_{z}\right.$ in figure 7) by oxygen (cf. reference [58]). Further increase of the oxygen concentration leads to a significant drop in catalytic activity. The in situ XAS results indicate that under oxygen-rich conditions palladium is oxidized on the surface leading to decreased activity, e.g., less reduced surface sites are available for alcohol adsorption and oxidation. In this respect, the observation is interesting that the catalyst reactivates "onstream" when the oxygen/reactant ratio in the feed is decreased again. Although reactivation of the catalyst by variation of the oxygen concentration turned out to be reversible, some differences in the transient behavior to the new steady state was observed, probably due to reduction of $\mathrm{PdO}_{x}$ species on the surface. Also, the formation of carbonaceous products at low conversion may have an influence. Reduction of $\mathrm{PdO}_{x} / \mathrm{Al}_{2} \mathrm{O}_{3}$ occurred substantially only at temperatures $>70{ }^{\circ} \mathrm{C}$. Since we observed a smaller reaction rate at lower temperatures (not shown), surface oxidation by oxygen seems to be favored compared to the dehydrogenation reactions at lower temperatures, leading additionally to a less-active catalyst.

The inhibiting effect of surface $\mathrm{PdO}_{x}$ species ("overoxidation" or "oxygen poisoning") has also been observed in liquid-phase oxidation, and thus the results are in qualitative accordance with the results from liquid-phase oxidation in toluene or water over $\mathrm{Pd} / \mathrm{Al}_{2} \mathrm{O}_{3}$ and $\mathrm{Pt} / \mathrm{Al}_{2} \mathrm{O}_{3}$ catalysts $[32,33,50,51,58,59]$. However, the turnover frequency is higher $\left(>1000 \mathrm{~h}^{-1}\right)$ using "supercritical" carbon dioxide. In addition, the optimum concentration of oxygen in the feed is significantly higher than in the liquid-phase oxidation. This may be due to the improved diffusivity of the reactants and products. In liquid-phase oxidation, optimum conditions were observed if palladium was in reduced state due to fast dehydrogenation and masstransport limitation of oxygen $[33,51,60]$. In the present study, we also observed that most of palladium is in a reduced state under optimum conditions. Nevertheless, some of the palladium is in oxidized state and thus the "overoxidation" effect is altered compared to liquidphase oxidation over palladium-based catalysts using organic solvents.

\section{Conclusions}

Noble-metal-catalyzed catalytic oxidation of benzyl alcohol was performed in "supercritical" carbon dioxide using an in situ spectroscopic cell that allows to combine structural investigation by X-ray absorption spectroscopy and catalytic studies. The presented setup is suited for dense fluids up to $200 \mathrm{bar}$, operates under continuous-flow conditions, and takes safety aspects into account. This approach provides the possibility to elucidate structure-activity relationships at the solid/ fluid interphase in dense or "supercritical" fluids.

In situ monitoring of the reduction of an aluminasupported palladium catalyst by benzyl alcohol in "supercritical" carbon dioxide, to our knowledge, presents the first example, where X-ray absorption spectroscopy was used to uncover dynamic changes of the structure of solid catalysts in SCFs or at elevated pressure (150 bar). Benzyl alcohol oxidation in "supercritical" carbon dioxide is more effective than in gas phase or liquid phase. The reaction rate goes through a maximum when the oxygen/alcohol ratio is increased. The simultaneously performed EXAFS studies uncovered that palladium is only partly oxidized if the oxygen concentration is increased to its optimum. At higher oxygen concentration, the activity decreases because the noble metal catalyst is in an "overoxidized" state.

\section{Acknowledgments}

We thank several people and institutions who/which have supported our work: HASYLAB (DESY, Hamburg, D) is gratefully acknowledged for providing beamtime for our in situ XAS studies. We thank M. Herrmann, P. Kappen, and the safety group at HASYLAB for their support and the constructive discussion of the safety aspects. P. Trüssel and M. 
Wohlwend from our workshop are acknowledged for their help in the construction of the in situ setup. Pressure tests were performed at SITEC Sieber Engineering AG (Maur/Zürich, $\mathrm{CH}$ ) and we particularly thank B. Zehnder for his help. We also express thanks for valuable discussion and help to C. Keresszegi, T. Mallat, S. Hannemann, M. Schneider (ETH), and K. Pickel (NWA, Lörrach, D).

\section{References}

[1] B. Subramaniam and M.A. McHugh, Ind. Eng. Chem. Process Des. Dev. 25 (1986) 1.

[2] P.G. Jessop, T. Ikariya and R. Noyori, Chem. Rev. 99 (1999) 475.

[3] P.G. Jessop and W. Leitner, Chemical Synthesis Using Supercritical Fluids (Wiley-VCH, Weinheim, 1999).

[4] P.E. Savage, in Handbook of Heterogeneous Catalysis, G. Ertl, H. Knözinger and J. Weitkamp (eds) Vol. 3 (Wiley-VCH, Weinheim, 1997), p. 1339.

[5] A. Baiker, Chem. Rev. 99 (1999) 453.

[6] J.R. Hyde, P. Licence, D. Carter and M. Poliakoff, Appl. Catal., A 222 (2001) 119.

[7] J.D. Grunwaldt, R. Wandeler and A. Baiker, Catal. Rev.-Sci. Eng. 45 (2003) 1.

[8] R. Wandeler, N. Künzle, M.S. Schneider, T. Mallat and A. Baiker, J. Catal. 200 (2001) 377.

[9] G. Jenzer, D. Sueur, T. Mallat and A. Baiker, Chem. Commun. (2000) 2247.

[10] G. Jenzer, M.S. Schneider, R. Wandeler, T. Mallat and A. Baiker, J. Catal. 199 (2001) 141.

[11] A.M. Steele, J. Zhu and S.C. Tsang, Catal. Lett. 73 (2001) 9.

[12] R. Gläser, R. Jos and J. Williardt, Top. Catal. 22 (2003) 31.

[13] A. Kordikowski and M. Poliakoff, Fluid Phase Equilib. 151 (1998) 493.

[14] R. Wandeler and A. Baiker, Chimia 53 (1999) 566.

[15] J. Ke, B. Han, M.W. George, H. Yan and M. Poliakoff, J. Am. Chem. Soc. 123 (2001) 3661.

[16] W.R. Moser, B.J. Marshik-Guerts and S.J. Okrasinski, J. Mol. Catal. A 143 (1999) 57.

[17] M.G. Süer, Z. Dardas, Y.P. Lu, W.R. Moser and Y.H. Ma, AIChE J. 44 (1997) 768.

[18] M. Fernandez-Garcia, Catal. Rev. Sci. Eng. 44 (2002) 59.

[19] G. Sankar, F. Rey, J.M. Thomas, G.N. Greaves, A. Corma, B.R. Dobson and A.J. Dent, Chem. Commun. (1994) 2279.

[20] I.J. Shannon, T. Maschmeyer, G. Sankar, J.M. Thomas, R.D. Oldroyd, M. Sheehy, D. Madill, A.M. Waller and R.P. Townsend, Catal. Lett. 44 (1997) 23.

[21] B.S. Clausen, L. Grabaek, G. Steffensen, P.L. Hansen and H. Topsøe, Catal. Lett. 20 (1993) 23.

[22] D. Bazin, H. Bexpert and J. Lynch, in X-ray Absorption Fine Structure For Catalysts and Surfaces, Y. Iwasawa, (ed), Vol. 2 (World Scientific, Singapore, 1996), p. 113.

[23] G. Meitzner, S.R. Bare, H. Woo and D.A. Fischer, Rev. Sci. Instr. 69 (1998) 2618.

[24] J.D. Grunwaldt and B.S. Clausen, Top. Catal. 18 (2002) 37.

[25] A.J. Dent, Top. Catal. 18 (2002) 27.

[26] J.-D. Grunwaldt, A.M. Molenbroek, N.-Y. Topsøe, H. Topsøe and B.S. Clausen, J. Catal. 194 (2000) 452.
[27] B.S. Clausen, L. Gråbæk, G. Steffensen, P.L. Hansen and H Topsøe, Catal. Lett. 20 (1993) 23.

[28] T. Ressler, M. Hagelstein, U. Hatje and W. Metz, J. Phys. Chem. B 101 (1997) 6680.

[29] J.-D. Grunwaldt, P. Kappen, L. Basini and B.S. Clausen, Catal. Lett. 78 (2002) 13.

[30] J.-D. Grunwaldt, L. Basini and B.S. Clausen, J. Catal. 200 (2001) 321.

[31] H.H.C.M. Pinxt, B.F.M. Kuster, D.C. Koningsberger and G.B. Marin, Catal. Today 39 (1998) 351.

[32] A.P. Markusse, B.F.M. Kuster, D.C. Koningsberger and G.B. Martin, Catal. Lett. 55 (1998) 141.

[33] J.-D. Grunwaldt, C. Keresszegi, T. Mallat and A. Baiker, J. Catal. 213 (2003) 191.

[34] R.A. DallaBetta, M. Boudart, K. Foger, D.G. Löffler and J. Sánchez-Arrieta, Rev. Sci. Instr. 55 (1984) 1910.

[35] B.S. Clausen and H. Topsøe, Catal. Today 9 (1991) 189.

[36] K.K. Bando, T. Saito, K. Sato, T. Tanaka, F. Dumeignil, M. Imamura, N. Matsubayashi and H. Shimada, J. Synchrotron Radiat 8 (2001) 581.

[37] T. Murata, K. Nakagawa, A. Kimura, N. Otoda and I. Shimoyana, Rev. Sci. Instrum. 66 (1995) 1437.

[38] S.L. Wallen, D.M. Pfund, J.L. Fulton, C.R. Yonker, M. Newville and Y. Ma, Rev. Sci. Instrum. 67 (1996) 2843.

[39] W.A. Bassett, A. H. Shen and M. Bucknum, Rev. Sci. Instr. 64 (1993) 2340.

[40] J.L. Fulton, J.G. Darab and M.M. Hoffmann, Rev. Sci. Instrum. 72 (2001) 2117.

[41] S.L. Wallen, B.J. Palmer, D.M. Pfund, J.L. Fulton, M. Newville, Y. Ma and E.A. Stern, J. Phys. Chem. A 101 (1997) 9632.

[42] S.L. Wallen, B.J. Palmer and J.L. Fulton, J. Chem. Phys. 108 (1998) 4039.

[43] J.L. Fulton, D.M. Pfund, S.L. Wallen, M. Newville, E.A. Stern and Y. Ma, J. Chem. Phys. 105 (1996) 2161.

[44] Y. Calzavara, V. Simonet, J.L. Hazemann, R. Argoud, O. Geaymond and D. Raoux, J. Synchrotron Radiat 8 (2001) 178.

[45] V. Simonet, Y. Calzavara, J.L. Hazemann, R. Argoud, O. Geaymond and D. Raoux, J. Chem. Phys. 116 (2002) 2997.

[46] G. Sankar, P.A. Wright, S. Natarajan, J.M. Thomas, G.N Greaves, A.J. Dent, B.R. Dobson, C.A. Ramsdale and R.H. Jones, J. Phys. Chem. 97 (1993) 9550.

[47] G. Sankar and J.M. Thomas, Top. Catal. 8 (1999) 1.

[48] B.S. Clausen, Catal. Today 39 (1998) 293.

[49] T. Ressler, J. Synchrotron Radiat 5 (1998) 118.

[50] T. Mallat and A. Baiker, Catal. Today 24 (1995) 143.

[51] M. Besson and P. Gallezot, Catal. Today 57 (2000) 127.

[52] R. Frahm, Physica B 158 (1989) 342.

[53] H. Topsøe, Stud. Surf. Sci. Catal. 130 (2000) 1.

[54] B.M. Weckhuysen, Chem. Commun. (2002) 97.

[55] H. Topsøe, J. Catal. 216 (2003) 155.

[56] J.-D. Grunwaldt, M. Maciejewski and A. Baiker, Phys. Chem. Chem. Phys. 5 (2003) 1481.

[57] A.L. Ankudinov, B. Ravel, J.J. Rehr and S.D. Conradson, Phys. Rev. B 58 (1998) 7565.

[58] C. Keresszegi, T. Bürgi, T. Mallat and A. Baiker, J. Catal. 211 (2002) 244.

[59] T. Mallat and A. Baiker, Catal. Today 19 (1994) 247.

[60] C. Keresszegi, J.-D. Grunwaldt, T. Mallat and A. Baiker, Chem. Commun. (submitted). 